\title{
INELEGIBILIDADE ELEITORAL E RECONHECIMENTO DA UNIÃO HOMOAFETIVA COMO ENTIDADE FAMILIAR: ANÁLISE DAS TENSÕES ENTRE IGUALDADE E DIFERENÇA NO JULGAMENTO DO RECURSO ESPECIAL ELEITORAL 24564 NO TRIBUNAL SUPERIOR ELEITORAL
}

\section{ELEGIBILITY REQUIREMENTS AND RECOGNITION OF HOMOSEXUAL CIVIL PARTNERSHIP: ANALYSIS OF THE TENSIONS BETWEEN EQUALITY AND DIFFERENCE IN THE JUDGMENT OF THE ELECTORAL SPECIAL APPEAL 24564 AT THE SUPERIOR ELECTORAL COURT}

\author{
${ }^{1}$ Bernardo Brasil Campinho
}

\section{RESUMO}

Este trabalho tem por objetivo analisar as tensões entre igualdade e diferença no constitucionalismo brasileiro contemporâneo tendo como referencial de análise o julgamento do Recurso Especial Eleitoral n. 24564/2004 no Tribunal Superior Eleitoral, decisão que reconheceu a união homoafetiva como entidade familiar e, a partir da revisão de literatura sobre democracia e direitos políticos, identificar a importância de compatibilizar igualdade e diferença no campo político, não somente pela via dos direitos, mas também pela ótica dos deveres, remetendo à necessidade de proteger a lisura da competição eleitoral para evitar a apropriação do espaço público por razões privadas de ordem familiar.

Palavras-chave: Inelegibilidade eleitoral, União homoafetiva, Igualdade, Diferença

\begin{abstract}
This work aims to analyze the tensions between equality and difference in contemporary Brazilian constitutionalism using as a reference the Electoral Special Appeal no. 24564/2004 at the Superior Electoral Court, which recognizes the homosexual civil partnership as a family entity, using the link between literature review on democracy and political rights to identify the importance of reconciling equality and difference in the political field, not only by way of rights, but also from the perspective of the duties, referring to the need to protect the fairness of electoral competition to avoid the appropriation of public space by private family reasons.
\end{abstract}

Keywords: Elegibility requeriments, Homosexual civil partnership, Equality, Difference

\footnotetext{
${ }^{1}$ Docente na Universidade Federal Rural do Rio de Janeiro (UFRRJ), Rio de Janeiro. (Brasil). E-mail: bbcampinho@yahoo.com.br
} 


\section{Introdução}

Este artigo tem por objetivo analisar as tensões entre igualdade e diferença tendo como referencial de análise o julgamento do Recurso Especial Eleitoral n. 24564, julgado no Tribunal Superior Eleitoral brasileiro no ano de 2004, a primeira decisão de um Tribunal Superior no país a reconhecer a união entre pessoas do mesmo sexo como entidade familiar e a traçar seus impactos no âmbito da esfera pública.

Para cumprir esta tarefa, este trabalho articular revisão de literatura sobre teoria democrática, igualdade e diferença com um estudo de caso, tendo por objeto o referido recurso especial eleitoral no Tribunal Superior Eleitoral brasileiro, buscando identificar o impacto que as conclusão do julgamento projetaram sobre o constitucionalismo brasileiro.

Para tanto, será feita uma análise teórica das correlações entre democracia e direitos políticos à luz das perspectivas de Robert Dahl, Norberto Bobbio e Chantal Mouffe, procurando estabelecer a democracia como um processo fundado na universalidade de acesso e participação no espaço público.

Em um segundo momento do texto, será delimitado o campo de incidência dos direitos políticos negativos, em particular do instituto das inelegibilidades, e sua importância na preservação da competição democrática e sua função na proteção à captura do espaço político por interesses familiares.

A terceira parte do trabalho consistirá na análise do Recurso Especial Eleitoral $\mathrm{n}$. 24564 e da discussão sobre o reconhecimento das entidades familiares formadas por pessoas do mesmo sexo como contraponto entre as pretensões de singularidade das identidades e as necessidades de respeito aos deveres e exigências subjacentes à idéia de um espaço público democrático e republicano - neste ponto, será feito um diálogo entre os principais pontos do julgamento e a teoria democrática no pensamento de Jean L. Cohen.

Ao final, serão traçadas as conclusões sobre as contribuições que o julgamento do Recurso Especial Eleitoral n. 24564 trouxe para o constitucionalismo brasileiro, particularmente na delimitação das tensões e interações entre democracia, universalidade e particularidade. 
Inelegibilidade Eleitoral e Reconhecimento da União Homoafetiva como Entidade Familiar: Análise das

Embora seja uma decisão do Tribunal Superior Eleitoral de 2004, o referido Recurso Especial Eleitoral n. 24564 apresenta a primeira vez em que os Tribunais Superiores reconheceram a união entre pessoas do mesmo sexo como entidade familiar, e mostra a importância de compatibilização igualdade e diferença no que se refere ao campo político, não somente pela via dos direitos, mas também pela ótica dos deveres, e remete à necessidade de proteger a lisura da competição política como forma de evitar a apropriação do espaço público por razões privadas de ordem familiar.

\section{1) Cidadania, democracia e a fundamentalidade dos direitos políticos}

Falar em direitos políticos significa abordar as duas matrizes centrais do Estado Constitucional no seu estágio de desenvolvimento atual: a democracia enquanto regime político e social e os direitos humanos fundamentais da pessoa humana e dos grupos como contraponto aos poderes político, social e econômico (CAMPINHO, 2013, p. 285).

Por um lado, é possível resgatar a história dos direitos fundamentais como sendo, de certa forma, uma história da limitação do poder (SARLET, 2007); neste sentido, a racionalização do poder político que é promovida pelos direitos humanos é tributária da participação política livre e democrática viabilizada pelo sufrágio universal e pelas diversas formas de atuação política por meio de associações, partidos e movimentos sociais.

Assim, a democracia é um processo dinâmico inerente a uma sociedade aberta e ativa, oferecendo aos cidadãos a possibilidade de desenvolvimento integral, liberdade de participação política crítica no processo político, condições de igualdades econômica, política e social (CANOTILHO, 1999).

A democracia não é apenas mais uma opção de regime dentre tantas outras igualmente disponíveis em todos os momentos e lugares, mas mais propriamente constitui uma resposta a desafios e a aspirações históricos, o que transforma o autogoverno popular em uma narrativa (DALLMAYR, 2001), que necessita por sua vez da participação dos indivíduos e dos grupos para ser tecida e construída.

Neste contexto, a liberdade de participação política do cidadão, como possibilidade de intervenção no processo decisório e, em decorrência, do exercício de efetivas contribuições 
inerentes à soberania (direito de voto, igual acesso aos cargos públicos etc.), constitui a toda evidência, complemento indispensável das demais liberdades (SARLET, 2007).

Nestes termos, direito democrático de participação do povo no governo, por seus representantes, acabou exigindo a formação de um conjunto de normas legais pertinentes, que recebeu a denominação de "direitos políticos", consistindo na disciplina dos meios necessários ao exercício da soberania popular (SILVA, 2006).

Quando tratamos dos direitos políticos estamos nos referindo ao direito à participação no processo político, ao direito ao sufrágio universal e ao voto periódico, livre, direto, secreto e igual, à autonomia de organização do sistema partidário, à igualdade de oportunidade dos partidos (MENDES, 2008).

Os direitos políticos garantem alguns dos elementos mais caros ao regime democrático: a manifestação livre e igualitária da soberania popular por meio de eleições livres, com competição entre grupos de ideologias e programas políticos diferentes, permitindo a alternância de poder e garantindo o amplo acesso aos órgãos políticos pelos cidadãos (CAMPINHO, 2013, p. 286).

Neste sentido, os direitos políticos são parte daquilo que Norberto Bobbio (2007, p. 327) chama de regras do jogo democrático ou "procedimentos universais", caracterizados pelos seguintes elementos:

\begin{abstract}
1) Órgão político máximo, a quem é assinalada a função legislativa, composto de membros direta ou indiretamente eleitos pelo povo, em eleições de primeiro ou segundo grau; 2) Existência junto ao supremo órgão legislativo de outras instituições com dirigentes eleitos, como os órgãos de administração local ou o chefe de Estado nas Repúblicas; 3) Todos os cidadãos que tenham atingido a maioridade, sem distinção de raça, de religião, de sexo, devem ser eleitores; 4) Todos os eleitores devem ser livres em votar segundo a sua própria opinião formada ou mais livremente possível, isto é, numa disputa livre de partidos políticos que lutam pela formação de uma representação nacional; 5) Igualdade de voto entre os eleitores; 6) Eleitores devem ter reais alternativas de escolha (o que exclui como democrática qualquer eleição de lista única ou bloqueada); 7) Prevalência do princípio majoritário; 8) As decisões da maioria não podem limitar os direitos da minoria, de um modo especial o direito de tornar-se maioria, em paridade de condições.
\end{abstract}

\footnotetext{
${ }^{1} \mathrm{O}$ núcleo central dos direitos políticos é o direito ao sufrágio, caracterizado como o direito de votar, de participar da organização da vontade estatal e no direito de ser votado, sendo que, no panorama constitucional brasileiro, o voto é obrigatório a partir dos 18 anos de idade para todos os brasileiros, natos ou naturalizados (MENDES, 2008); ao mesmo tempo, o voto é facultativo para os maiores de 16 anos e menores de 18 anos, para os maiores de 70 anos e para os analfabetos. Quanto às modalidades de direitos políticos, estes podem ser considerados, quanto ao modo de exercício, direitos políticos ativos ou direitos políticos passivos, sendo os primeiros consubstanciados nas condições do direito de votar (capacidade eleitoral ativa) e à capacidade eleitoral passiva, que é expressa por meio das elegibilidades, ou seja, atributo de quem tem a condição de ser votado (SILVA, 2006). Outra divisão pode ser feita entre direitos políticos positivos e negativos, sendo os primeiros o conjunto de normas que asseguram o direito subjetivo de participação no processo político e nos órgãos governamentais, incluindo o direito de sufrágio, o direito à elegibilidade, o direito de voto em plebiscitos e referendos, a iniciativa popular, o direito a propor ação popular e o direito de organizar e participar de partidos políticos (SILVA, 2006). Já os direitos políticos negativos se consubstanciam nas determinações constitucionais que importem em privar o cidadão do direito de participação no processo político e nos órgãos governamentais, o que inclui as regras constitucionais sobre suspensão e perda de direitos políticos, bem como as restrições à elegibilidade do cidadão (inelegibilidades).
} 
Inelegibilidade Eleitoral e Reconhecimento da União Homoafetiva como Entidade Familiar: Análise das

Da mesma forma que Norberto Bobbio, Robert Dahl (2001) também procura estabelecer critérios a que o governo de uma associação teria que responder, para satisfazer a exigência de que todos os membros da associação estejam igualmente capacitados a participar das decisões.

Em outras palavras, quais seriam os critérios para identificar um governo democrático? Dahl propõe critérios que fundamentam ou inspiram os direitos políticos: participação efetiva, igualdade de voto, aquisição de entendimento esclarecido, exercício do controle do planejamento (agenda democrática) e inclusão dos adultos (todos).

Pelo critério da participação efetiva, antes de ser adotada uma política pelo governo, todos os membros devem ter oportunidades iguais e efetivas para fazer os outros membros conhecerem sua opinião sobre qual deveria ser esta política (DAHL, 2001).

Pelo critério da igualdade de voto, quando chegar o momento em que a decisão sobre a política tiver de ser tomada, todos os membros devem ter oportunidades iguais e efetivas de votos e todos os votos devem ser contados como iguais (DAHL, 2001).

Já pelo critério do entendimento esclarecido, dentro de limites razoáveis de tempo, cada membro deve ter oportunidades iguais e efetivas de aprender sobre as políticas alternativas importantes e suas prováveis consequências (DAHL, 2001).

Quanto ao controle do planejamento (da agenda democrática), trata-se de garantir que todos devem ter a oportunidade exclusiva para decidir como e, se preferirem, quais as questões devem ser colocadas, tornando as políticas sempre abertas para a mudança. Finalmente, a inclusão de todos (os adultos) implica na obrigatoriedade de que todos os adultos residentes permanentes devem ter o pleno direito de cidadãos (DAHL, 2001).

Note-se que Robert Dahl centra a sua análise nas condições que permitem a permanência da competição democrática e a inclusão de indivíduos e grupos no processo, evitando tratar de aspectos substantivos da idéia de democracia enquanto regime político como faz Bobbio, a exemplo da necessidade de conciliar o princípio majoritário e os direitos das minorias.

Note-se que a competição eleitoral democrática não necessariamente existe para produzir consensos, mas sim para estabelecer uma regulação do conflito no espaço público, como bem destaca Chantal Mouffe:

O objetivo da democracia não é que todo mundo se coloque de acordo, há posições irreconciliáveis. Critico as tradições teóricas que dizem que a política democrática busca consensos. Habermas indica que o consenso se busca através de processos deliberativos, argumentos racionais. Eu não concordo com ele. A política tem a ver com o conflito e a democracia consiste em dar possibilidade aos diferentes pontos de vista para que se 
manifestem e se desentendam. $\mathrm{O}$ dissenso pode se dar mediante o antagonismo amigoinimigo quando se trata o oponente como inimigo - no extremo levaria a uma guerra civil - ou através do que chamo agonismo: um adversário reconhece a legitimidade do oponente e o conflito se conduz através das instituições. É uma luta por hegemonia ${ }^{2}$.

Como explica Josedac Bezerra dos Santos, Chantal Mouffe Mouffe estabelece as bases para a defesa de sua teoria política, que, ao contrário da perspectiva liberal, sustenta a importância do dissenso numa sociedade democrática, estabelecendo assim o chamado "pluralismo agonístico" - a natureza radical da democracia estaria portanto na impossibilidade de eliminação do antagonismo ${ }^{3}$.

Neste contexto, os direitos políticos seriam compreendidos como elemento central da natureza radical da democrática, na medida em que seriam parâmetros pelos quais a competição política democrática poderia ocorrer a partir da demarcação do campo de atuação das forças políticas e a plena identificação dos antagonistas, criando parâmetros para a canalização do conflito político para as instituições eleitorais no espaço público democrático.

\section{2) Direitos políticos, inelegibilidades, relações familiares e democracia}

Os direitos políticos cumprem duas funções ao mesmo tempo: são formas de viabilizar a participação ativa da comunidade por meio do direito de voto e do processo eleitoral, no qual diversos grupos e interesses se apresentam, buscando conquistar o maior apoio possível dos demais cidadãos (direitos políticos positivos); e, para manter a idoneidade e a representatividade do processo de formação da vontade política da comunidade, consistem igualmente em determinações constitucionais que ora podem privar a pessoa de participar do processo político-eleitoral (suspensão e perda de direitos políticos), ora impõem restrições à elegibilidade (capacidade eleitoral passiva ou direito de ser votado) de alguém (direitos políticos negativos).

A importância deste último tipo de direitos políticos é inegável para manter o controle da agenda democrática nas mãos daqueles a quem ele realmente pertence: os cidadãos.

Para isso, as disposições constitucionais que impõem privações e restrições aos direitos políticos ativos e passivos devem ser compreendidas como forma de garantir a

\footnotetext{
2 Mouffe, Chantal. Entrevista concedida a Mercedes Lopez San Miguel do Página/12. Traduzida e disponibilizada em http://www.ihu.unisinos.br/noticias/noticias-anteriores/36103-a-politica-tem-a-ver-com-oconflito-entrevista-com-chantal-mouffe\%20. Acesso em 23 de agosto de 2015.

3 Santos, Josadac Bezerra dos. Chantal Mouffe e a filosofia política. Texto disponível em: http://revistacult.uol.com.br/home/2010/03/chantal-mouffe-e-a-filosofia-politica/. Acesso em 23 de agosto de 2015.
} 
isenção do processo, seja pela idoneidade dos participantes, seja pela garantia da livre formação da vontade política, por meio de eleições justas e regulares e também pela liberdade de expressão política, mantendo-a protegida tanto do poder econômico e político quanto de outras influências do poder social que podem corromper ou dirigir indevidamente o voto.

A vontade soberana do povo expressa, dentre outras formas, pelo processo eleitoral, deve assim ser plenamente garantida contra interferências indevidas, buscando valorizar ao máximo a universalidade do direito ao voto e garantir a igualdade de cada voto individual, de modo que não existam, pelo menos no plano normativo-constitucional, votos de primeira e segunda categorias. $^{4}$

A Constituição brasileira tratou dos direitos políticos no Título II, Capítulo IV, arts. 14 a 17, trazendo tanto restrições aos direitos políticos de cidadãos (art. 15), como um conjunto de limitações à capacidade eleitoral passiva (elegibilidade), estas dispostas no art. 14, parágrafos $4^{\circ}$ a $7^{\circ}$.

Uma das inelegibilidades trazidas pela Constituição é aquela disposta no art. 14, parágrafo $7^{\circ}$, que estabelece que são inelegíveis, no território de jurisdição (circunscrição) do titular, o cônjuge e os parentes consangüíneos ou afins, até o segundo grau ou por adoção, do Presidente da República, de Governador de Estado ou Território, do Distrito Federal, de

\footnotetext{
${ }^{4}$ Seguramente existe a igualdade do direito de voto ("one person one vote") como ideal fundamental sobre a qual se assenta a participação política democrática. Mas é preciso reconhecer que, no plano da Ciência Política, o comportamento dos atores políticos no processo eleitoral e os traços da política empírica, a partir do sistema eleitoral proposto (distrital, proporcional ou misto) e das diversas regras que lhe são conexas (partidos políticos, direito de voto, financiamento eleitoral etc.), acabam por estabelecer que em certas circunstâncias votos de certas regiões, distritos eleitorais, classe ou gênero têm maior peso do que em relação a outros. A distribuição de assentos parlamentares também influencia a importância que cada circunscrição e os votos dos cidadãos que nela se encontram pode receber. Nas eleições norte-americanas, amparadas pelo signo do colégio eleitoral, faz muito mais sentido para um candidato investir pesadamente na campanha na Califórnia, Estado com o maior número de votos no colégio eleitoral, do que em Guam ou Montana. Diversos países admitem votos de cidadãos no exterior, militares em serviço fora do país, mas dificilmente, do ponto de visto político, uma campanha centraria seus esforços neste conjunto de eleitores em detrimento, por exemplo, de ações voltadas para habitantes de grandes cidades, mulheres ou qualquer outro grupo social com significativo peso eleitoral. No Brasil, o percentual de votos necessário para eleger um deputado federal no Acre sem necessidade de votos de legenda (12,5\% para cada uma das oito vagas) é muito superior ao percentual exigido em São Paulo (1,43\% para cada uma das setenta vagas), embora em número de eleitores exigidos no último caso, em virtude do tamanho da população eleitoral, seja muito superior em relação ao primeiro caso - neste sentido, a combinação de diversos fatores (cadeiras em disputa, número de eleitores, número de candidatos, número de partidos em disputa, votos válidos etc.) torna muito desigual a relação entre um voto no Acre e outro em São Paulo, no que tange o seu peso efetivo ou sua importância para eleger um deputado federal sem necessidade de outros votos de legenda. Do ponto de vista de política empírica por assim dizer, nenhum voto é igual ao outro e os votos possuem pesos e importâncias distintas, quando comparados em termos quantitativos ou qualitativos. No entanto, para fins de Direito Constitucional, os votos são iguais no sentido de que contam igualmente na formação da vontade política da comunidade e não podem ser diferenciados por quaisquer critérios uma vez que sejam considerados válidos. Esta concepção de ordem normativa, com pretensão de validade, não desmente em nada as considerações anteriores, apenas coloca em evidência um aspecto de universalidade e igualdade dos direitos políticos, sem, no entanto, interferir nos cenários empíricos analisados pela Ciência Política, particularmente pelos estudos de comportamento eleitoral, nos quais os votos assumem, à luz dos fatores já enunciados, pesos diferentes em circunstâncias diferentes.
} 
Prefeito ou de quem os haja substituído dentro dos seis meses anteriores ao pleito, salvo se já titular de mandato eletivo e candidato à reeleição.

Esta inelegibilidade é chamada de reflexiva, pois o impedimento para concorrer às eleições recai sobre determinadas pessoas por motivo de casamento, parentesco ou afinidade, e seu escopo é evitar o nepotismo e a perpetuação do poder hereditário (BULOS, 2008).

No Recurso Extraordinário número 344.882, julgado pelo Supremo Tribunal Federal em 7 de abril de 2003 e tendo como relator o Ministro Sepúlveda Pertence, ficaram assentados os fundamentos da inelegibilidade reflexiva ou decorrente de parentesco, conforme pode-se conferir na ementa a seguir transcrita:

\begin{abstract}
EMENTA: Elegibilidade: cônjuge e parentes do chefe do Poder Executivo: elegibilidade para candidatar-se à sucessão dele, quando o titular, causador da inelegibilidade, pudesse, ele mesmo, candidatar-se à reeleição, mas se tenha afastado do cargo até seis meses antes do pleito. 1. A evolução do Direito Eleitoral brasileiro, no campo das inelegibilidades, girou durante décadas em torno do princípio basilar da vedação de reeleição para o período imediato dos titulares do Poder Executivo: regra introduzida, como única previsão constitucional de inelegibilidade, na primeira Carta Política da República (Const. 1891, art. 47, § $4^{\circ}$ ), a proibição se manteve incólume ao advento dos textos posteriores, incluídos os que regeram as fases de mais acendrado autoritarismo (assim, na Carta de 1937, os art. 75 a 84, embora equívocos, não chegaram à admissão explícita da reeleição; e a de 1969 (art. 151, §

$1^{\circ}$, a) manteve-lhe o veto absoluto). 2. As inspirações da irreelegibilidade dos titulares serviram de explicação legitimadora da inelegibilidade de seus familiares próximos, de modo a obviar que, por meio da eleição deles, se pudesse conduzir ao continuísmo familiar. 3. Com essa tradição uniforme do constitucionalismo republicano, rompeu, entretanto, a EC $16 / 97$, que, com a norma permissiva do $\S 5^{\circ}$ do art. $14 \mathrm{CF}$, explicitou a viabilidade de uma reeleição imediata para os Chefes do Executivo. 4. Subsistiu, no entanto, a letra do $\S 7^{\circ}$, atinente a inelegibilidade dos cônjuges e parentes, consanguíneos ou afins, dos titulares tornados reelegíveis, que, interpretado no absolutismo da sua literalidade, conduz a disparidade ilógica de tratamento e gera perplexidades invencíveis. 5. Mas, é lugar comum que o ordenamento jurídico e a Constituição, sobretudo, não são aglomerados caóticos de normas; presumem-se um conjunto harmônico de regras e de princípios: por isso, é impossível negar o impacto da Emenda Constitucional $n^{\circ} 16$ sobre o $§ 7^{\circ}$ do art. 14 da Constituição, sob pena de consagrar-se o paradoxo de impor-se ao cônjuge ou parente do causante da inelegibilidade o que a este não se negou: permanecer todo o tempo do mandato, se candidato à reeleição, ou afastar-se seis meses, para concorrer a qualquer outro mandato eletivo. 6. Nesse sentido, a evolução da jurisprudência do TSE, que o STF endossa, abandonando o seu entendimento anterior (BRASIL. STF, 2003).
\end{abstract}

Nesta linha de desenvolvimento, Gilmar Mendes (2007) recorda que há muito o Tribunal Superior Eleitoral entende que a restrição à candidatura do cônjuge abrange também a do companheiro ou companheira, a do irmão, a da concubina.

Na própria página do Tribunal Superior Eleitoral na internet podem ser encontrados esclarecimentos que corroboram a assertiva do referido autor, conforme se depreende da citação de trecho do material disponível na seção dos julgados históricos acerca do caso Viseu: 


\begin{abstract}
A interpretação do dispositivo constitucional supramencionado, no que diz respeito ao cônjuge, evoluiu para abranger outras situações não previstas expressamente: casamento eclesiástico, concubinato e união estável são também considerados circunstâncias de natureza pessoal causadoras de inelegibilidade reflexa, igualmente ao casamento (BRASIL. TSE, 2009).
\end{abstract}

Sobre esta inelegibilidade reflexiva dois esclarecimentos precisam ser feitos. Primeiro, ela não impede que familiares e parentes se candidatem em períodos posteriores aos governantes com os quais têm relação de parentesco, não impedindo, por exemplo, que o filho de um governador de Estado pleiteie a prefeitura de um Município daquele mesmo Estado federado vários anos depois de seu pai ter deixado o cargo, mas apenas que isto ocorra em um período concomitante ou imediatamente sucessivo ao exercício do cargo por parente ou familiar no rol descrito no parágrafo $7^{\circ}$ do art. 14 da Constituição.

Ainda, a restrição não impede o exercício concomitante ou mesmo sucessivo de cargos eletivos no legislativo, dirigindo-se primordialmente aos cargos do Poder Executivo. ${ }^{5}$

A segunda observação é no sentido de que a inelegibilidade reflexa disposta no parágrafo $7^{\circ}$ do art. 14 da Constituição brasileira é uma norma de Direito Constitucional positivo pátrio que não guarda necessariamente relação com outras realidades constitucionais.

Basta mencionar que recentemente Cristina Kirchner, reeleita Presidenta da República Argentina em duas ocasiões (2007 e 2011), havia sucedido de forma imediata seu marido, Nestor Kirchner, falecido em 2010 e que havia governado a Argentina no período imediatamente anterior (2003-2007) ao corrente governo da atual Presidenta. Em sistemas parlamentaristas, podemos indicar o exemplo da Índia, onde Rajiv Gandhi sucedeu sua mãe, Indira Gandhi, no cargo de primeiro-ministro, após o assassinato dela em 1984.

No mesmo sentido que a Constituição brasileira, a Constituição da Guatemala (REPÚBLICA DE GUATEMALA, 2011) dispõe, no seu art. 186, letra c, que não podem candidatar-se ao cargo de Presidente e Vice-Presidente da República os parentes até o quarto grau de consanguinidade e até o segundo grau de afinidade do Presidente ou do Vice-

\footnotetext{
${ }^{5}$ A política brasileira está cheia de vários exemplos de parlamentares de diferentes casas legislativas ou até na mesma casa legislativa, podendo ser citados somente no Congresso Nacional e na legislatura 2011-2014: Senador Capiberibe e sua esposa, Deputada Janete Capiberibe; o Ministro da Previdência Social e Senador licenciado Garibaldi Alves Filho e seu pai, o também Senador Garibaldi Alves (assumiu no lugar da ex-Senadora Rosalba Ciarlini, que assumiu mandato de Governadora do Rio Grande do Norte em $1^{\circ}$ de janeiro de 2011, dentre outros. Quanto a familiares de ocupantes de cargos de Chefe de Estado e de Governo em Repúblicas, podemos citar os diversos membros das famílias Gandhi e Nehru que exerceram postos políticos entre a década de 1940 e os dias atuais, como Mahatma Gandhi, Indira Gandhi (filha de Jawaharlal Nehru e casada com um filho de Gandhi), Rajiv Gandhi (filho de Indira, que inclusive a sucedeu, após seu assassinato); nos Estados Unidos, George H.W.Bush foi Presidente da República entre 1989 e 1993, enquanto seu filho, George W. Bush, foi Presidente de 2001 a 2009; e no Chile, Eduardo Frei Montalva foi Presidente da República entre 1964 e 1970 e seu filho, Eduardo Frei Ruiz-Tagle foi Presidente da República entre 1994 e 2000.
} 
Presidente da República, quando este estiver exercendo a Presidência. ${ }^{6}$

\section{3) O julgamento do Recurso Especial Eleitoral n. $24564^{7}$ no Tribunal Superior Eleitoral}

A questão da inelegibilidade em razão de parentesco ou vínculo conjugal ou familiar foi ponto de controvérsia judicial no âmbito da Justiça Eleitoral brasileira quando se tratou de saber se se poderia estender a proibição do parágrafo $7^{\circ}$ do art. 14 da Constituição a uma relação homoafetiva que não se encontra expressamente reconhecida como entidade familiar ou vínculo conjugal no Código Civil e que só seria reconhecida como união estável em 2011 no célebre julgamento da Ação Direta de Inconstitucionalidade n. 4277 no âmbito do Supremo Tribunal Federal.

Isto ocorreu no julgamento do Recurso Especial Eleitoral número 24.564 do Tribunal Superior Eleitoral, decidido pelo pleno do TSE em outubro de 2004. A primeira evidência da importância do caso se encontra no fato de ser o único dos julgamentos citados pelo Tribunal Superior Eleitoral entre os considerados históricos no período entre 2000 e 2009 na sessão dedicada à memória dos julgamentos históricos da Justiça Eleitoral no site do Tribunal (BRASIL. TSE, 2009), o que se mostra emblemática considerando que o mesmo período foi palco de decisões de importância capital para a democracia brasileira, casos da verticalização das coalizões eleitorais (2002) e da fidelidade partidária (2007), ainda que, em ambos os casos, a palavra final sobre o assunto tenha sido dada em recurso ou processo posteriormente ajuizado no Supremo Tribunal Federal.

O caso em questão se torna assim relevante para a análise do tema deste trabalho na

\footnotetext{
${ }^{6}$ Esta disposição constitucional foi objeto de controvérsia judicial recente envolvendo o Ex-Presidente da Guatemala, Álvaro Colom (2008-2012) e sua (ex?) esposa, Sandra Torres, visto que os dois se divorciaram para que ela pudesse concorrer à eleição presidencial guatemalteca de 2011 no lugar de Álvaro Colom, mas a pretensão foi rejeitada com base no art. 186, c, da Constituição da Guatemala, tanto pelo Supremo Tribunal de Justiça, por 12 votos a 1, bem como pelo Tribunal Constitucional, por unanimidade, por entenderem ambas as instâncias judiciais que o divórcio do casal era uma forma de fraudar ou burlar o intento e a disposição da mencionada norma constitucional guatemalteca (FOLHA DE SÃO PAULO, 2011). No Brasil, a súmula vinculante número 18 do Supremo Tribunal Federal adota solução neste mesmo sentido, ao dispor que a dissolução da sociedade ou do vínculo conjugal, no curso do mandato, não afasta a inelegibilidade prevista no parágrafo $7^{\circ}$ do art. 14 da Constituição brasileira.

7 Segundo o art. 276 do Código Eleitoral brasileiro, as decisões dos Tribunais Regionais Eleitorais são terminativas, salvo os casos em que cabe recurso para o Tribunal Superior, dentre eles o recurso especial, cabível nas seguintes hipóteses: a) quando forem proferidas contra expressa disposição de lei; b) quando ocorrer divergência na interpretação de lei entre dois ou mais tribunais eleitorais (informação disponível em: http://www.planalto.gov.br/ccivil_03/leis/14737.htm. Acesso em 24 de agosto de 2015).
} 
Inelegibilidade Eleitoral e Reconhecimento da União Homoafetiva como Entidade Familiar: Análise das

medida em que representou pela primeira vez nas instâncias superiores do Poder Judiciário brasileiro, e mesmo do Estado brasileiro como um todo, ${ }^{8}$ o reconhecimento das uniões homoafetivas como dignas de menção e consideração como entidade familiar e como portadoras de igual dignidade em termos de direitos e deveres perante o espaço público democrático, em relação a outros grupos e pessoas.

O Relator do Recurso Especial Eleitoral número 24564 foi o Ministro Gilmar Mendes, do Supremo Tribunal Federal, à época integrante do Tribunal Superior Eleitoral.

Conforme descrito no relatório, tratava-se originalmente da impugnação do registro de candidatura da Sra. Maria Eulina Rabelo de Sousa Fernandes ao cargo de Prefeita de Viseu no Pará. Conforme relatado, o pedido de registro de candidatura foi impugnado na primeira instância sob a alegação de que a Sra. Maria Eulina mantinha união estável com a então Prefeita reeleita do Município de Viseu/PA (BRASIL. TSE, 2004).

BRASIL. Tribunal Superior Eleitoral. Relatório do Recurso Especial Eleitoral número 24564. Relator: Min. Gilmar Mendes. Data do julgamento: 1\%10/2004.

O juiz eleitoral de primeira instância indeferiu o registro da candidata por considerar, a partir de uma interpretação extensiva, que o mesmo violava o art. 14, parágrafo $7^{\circ}$, da Constituição da República. Mas o Tribunal Regional Eleitoral do Pará reformou a sentença do juiz eleitoral de primeiro grau, invocando os seguintes fundamentos:

$[\ldots]$

1. Considera-se união estável, para a proteção de Estado, aquela que decorre da união entre homem e mulher como entidade familiar, dentro do que dispõe a Lei Civil em vigor.

2. Inexistência de previsão constitucional e infraconstitucional. A regra de inelegibilidade inserida no art. 14, parágrafo $7^{\circ}$, da Constituição Federal não atinge, nem mesmo de maneira reflexa, as relações homoafetivas, por não se enquadrar no conceito de relação estável e diante do silêncio eloquente do art. 226, parágrafo $3^{\circ}$, da Constituição.

3. A omissão do ordenamento jurídico que regulamente as relações homoafetivas e consequentemente as inelegibilidades decorrentes de tais relações não autoriza a aplicação por analogia das proibições decorrentes dos limites decorrentes das

\footnotetext{
${ }^{8}$ É bem verdade que o debate sobre direitos humanos relacionados à questão GLBT foram discutidos durante a assembléia (congresso) constituinte de 1987/1988 e que decisões judiciais de primeira e segunda instância, assim como certos setores da Administração Pública direta e indireta (principalmente no âmbito da União) já vinham há cerca de uma década promovendo as discussões sobre cidadania e direitos relacionados à homossexualidade e enfrentando as pretensões igualitárias postas por pessoas, grupos e movimentos ligados à questão da identidade fundada na orientação sexual, mas a decisão do TSE no REsp (Recurso Especial Eleitoral) 24.564 foi a primeira manifestação incisiva de reconhecimento do Estado brasileiro nas suas instância superiores de poder à identidade GLBT como parte do espaço público e como merecedora de igual consideração quanto a direitos e deveres, além de determinar em uma manifestação expressa de soberania (no caso, uma decisão judicial) que pessoas e grupos (familiares) ligados à identidade homossexual estão integrados na ordem jurídica e vinculados ao Estado de Direito como diretriz do espaço público e social na democracia republicana. Esclareça-se, no entanto, que antes e depois desta decisão Chefes de Estado no Brasil já haviam se manifestado politicamente como favorável a medidas de igualdade de gênero e de orientação sexual: o ex-Presidente Fernando Henrique Cardoso, em 2002 (LEPIANI, 2002) e o ex-Presidente Lula em 2008 (TERRA, 2008).
} 
relações de parentesco para o mandato eletivo, previstas na Constituição Federal e na Lei Complementar 64/90.

4. Considerando o princípio da legalidade, não incumbe ao intérprete ampliar o elenco de inelegibilidades o que conduziria a imiscuir na vontade do legislador. De igual modo, há de ser observado o princípio da isonomia material, não podendo ser restringidos direitos, sob pena de, a despeito da omissão legal, incorrer em inadmissível e inconcebível discriminação (BRASIL. TRE/PARÁ, 2004)

O Ministério Público Eleitoral, em conjunto com outros recorrentes, interpôs recurso especial eleitoral da decisão do Tribunal Regional Eleitoral do Pará, alegando, em síntese, que a falta de regulamentação das relações entre pessoas do mesmo sexo não pode afastar a vedação constitucional à perpetuação do mesmo grupo familiar no poder (BRASIL. TSE/PARÁ, 2004).

O Ministério Público Eleitoral junto ao Tribunal Superior Eleitoral, na pessoa do ViceProcurador-Geral Eleitoral, Dr. Roberto Gurgel, opinou pelo deferimento do recurso especial eleitoral, com o consequente indeferimento do pedido de candidatura da Sra. Maria Eulina.

Invocando a interpretação teleológica do art. 14 , parágrafo $7^{\circ}$, para destacar que o objetivo da norma constitucional consiste em impedir que grupos familiares se perpetuem no poder, o Vice-Procurador-Geral Eleitoral invocou a manifestação da Procuradoria da República no Pará, para destacar que a Sra. Maria Eulina convivia maritalmente com a então Prefeita de Viseu, da mesma forma que qualquer outra entidade familiar, e que a circunstância de a então Prefeita de Viseu já ter sido reeleita naquela oportunidade impedia a candidata citada de concorrer à sucessão da mandatária municipal, com quem havia formado relação estável e familiar.

Um dos argumentos aduzidos pela Procuradoria da República no Pará traçou um paralelo entre o caso em análise e o Recurso Extraordinário Eleitoral 98.935, julgado pelo STF em 1982, sob a relatoria do Min. Cordeiro Guerra, quando se assentou, igualmente por interpretação extensiva, que não se poderia considerar inelegível a esposa legítima (termo utilizado no

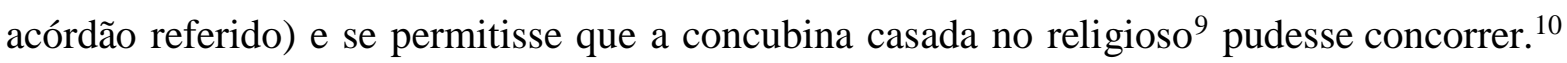

O referido acórdão do Supremo Tribunal Federal estendeu a inelegibilidade decorrente

\footnotetext{
${ }^{9}$ A expressão "concubina casada no religioso" é retirada do próprio voto do Min. Cordeiro Guerra e diz respeito à pessoa que contraiu casamento apenas no religioso, sem efeitos civis. Obviamente trata-se de manifestação contextualizada em época anterior à Constituição de 1988 e a toda legislação civil que, a partir dos anos 1990 , passou a reconhecer a união estável como entidade familiar, culminando na sua inclusão no Código Civil de 2002. Hoje, seria mais correto falar-se em união estável fundada em casamento exclusivamente religioso.

10 Comentários a partir da manifestação da Procuradoria da República no Pará no julgamento do Caso Viseu no Tribunal Regional Eleitoral do Pará, reproduzida a partir da manifestação do Vice-Procurador-Geral Eleitoral no REsp Eleitoral 24564 (BRASIL. TSE/PARÁ, 2004).
} 
Inelegibilidade Eleitoral e Reconhecimento da União Homoafetiva como Entidade Familiar: Análise das

do casamento civil à pessoa casada apenas no religioso justamente por considerar que o princípio que rege as inelegibilidades reflexas em decorrência de parentesco se aplica igualmente às duas situações, ou seja, o que se busca é impedir que grupos familiares apropriemse dos cargos eletivos, pervertendo a ideia de república ao tornar a esfera política objeto de apropriação privada de grupos familiares.

No seu voto, o Min. Gilmar Mendes relata que as provas examinadas indicavam a existência de união de fato e que o cerne da questão consistia em saber se a inelegibilidade reflexa prevista no art. 14 , parágrafo $7^{\circ}$, da Constituição poderia ser aplicada a uma relação homoafetiva.

O Min. Gilmar Mendes destaca, então, que situações como concubinato, união estável, casamento e parentesco compartilham um mesmo elemento, que enseja a aplicação da inelegibilidade reflexa: a presença de forte vínculo afetivo, capaz de unir pessoas em torno de interesses comuns (BRASIL. TSE/PARÁ, 2004), citando, à época, incipiente reconhecimento das relações homoafetivas pelos Tribunais Superiores brasileiros, ao menos em matéria patrimonial, particularmente o STJ e o STF. ${ }^{11}$

O Min. Gilmar Mender concluiu seu voto entendendo que os sujeitos de uma relação estável homoafetiva, à semelhança do que ocorre com os sujeitos de uma união estável ${ }^{12}$, de concubinato e de casamento, submetem-se à regra de inelegibilidade prevista no art. 14, parágrafo $7^{\circ}$, da Constituição da República.

Os demais Ministros do Tribunal Superior Eleitoral na ocasião seguiram o voto do Min. Gilmar Mendes e o recurso foi conhecido e provido, indeferindo o registro da candidatura da Sra. Maria Eulina.

\section{4) O legado do julgamento do Recurso Especial Eleitoral n. 24564/TSE para o constitucionalismo brasileiro: o equilíbrio entre universalidade democrática e as pretensões identitárias fundadas na diferença}

Dentre os votos destacados no julgamento do Recurso Especial Eleitoral n. 24564 no TSE, cabe destacar a manifestação do Min. Carlos Velloso, Vice-Presidente do TSE à época, que durante este julgamento estava no exercício da Presidência, declarando que:

\footnotetext{
${ }^{11}$ Especificamente quanto ao STF, o Min. Gilmar Mendes relembrou a PET 1984-9/RS, processo no qual houve o reconhecimento de companheira homossexual para fins previdenciários.

12 Após a decisão do STF no julgamento conjunto da ADI 4277 e da ADPF 132, em maio de 2011, foram equiparadas as figuras jurídicas da união homoafetiva e da união estável heterossexual para fins de proteção jurídica.
} 
O eminente relator demonstrou muito bem que o mundo evolui e é preciso reconhecer estas entidades que se formam. Desconhecer a realidade seria desconhecer o papel do Direito e, principalmente, do Direito Público.

O julgamento do Recurso Especial Eleitoral 24.564 no Tribunal Superior Eleitoral põe em evidência outro aspecto importante da igualdade de orientação sexual no que tange ao campo dos direitos políticos: a necessidade de cumprir os mesmos deveres e respeitar os mesmos limites que os demais membros da comunidade política.

Com efeito, uma das principais contribuições do Estado de Direito para a concepção de democracia constitucional contemporânea se funda profundamente da idéia de reciprocidade, que se desdobra em duas: a) reciprocidade entre Estado e indivíduo: como parte da sociedade política, o indivíduo se submete ao Direito posto pelo Estado na medida em que confia que a autoridade pública fará o mesmo, ou seja, que o Estado se vinculará ao Direito e à lei que produz; b) reciprocidade entre os indivíduos submetidos ao mesmo Estado e à mesma Constituição: traduzida nas concepções de paridade de tratamento e de igualdade perante a lei, significa dizer que os indivíduos, enquanto pessoas e enquanto cidadãos do Estado, estão submetidos à mesma autoridade política, com a qual mantém um vínculo baseado em direitos e deveres, mas também estão intimamente ligados ao outro por laços de solidariedade, tanto cívica quanto social, pela noção de direitos e responsabilidades compartilhados com o outro, igualmente integrante da comunidade política, um código de respeito mútuo baseado no que Max Weber chamar de ética da responsabilidade, ${ }^{13}$ a partir da qual a cidadania, enquanto inclusão de todos, é a convivência baseada no reconhecimento e observância de direitos e deveres dos indivíduos como cidadãos em relação ao Estado e entre si.

Não foi outra a posição de Maurizio Viroli, em diálogo travado com Norberto Bobbio na obra "Direitos e Deveres na República: os grandes temas da política e da cidadania", ao destacar a questão dos deveres nos seguintes termos:

[...] se você considera seriamente os direitos, precisa considerar seriamente os deveres: o dever de defender a liberdade comum, o dever de respeitar os direitos dos outros indivíduos. Talvez nós, laicos, falemos muito pouco dos deveres ${ }^{14}$ e muitos

\footnotetext{
${ }^{13}$ Silvio Ferrari, no verbete "Política" do Dicionário de Política coordenado por Bobbio, Mateucci e Pasquino, esclarece que o critério da ética da convicção é geralmente usado para julgar as ações individuais, enquanto o critério da ética da responsabilidade se usa ordinariamente para julgar as ações de grupo, ou praticadas por um indivíduo, mas em nome e por conta do próprio grupo, seja ele o povo, a nação, a Igreja, a classe, o partido etc. (apud BOBBIO; MATEUCCI; PASQUINO, 2007, p. 961).

${ }^{14}$ No diálogo que trava com Maurizio Viroli em “Direitos e Deveres na República”, Bobbio relembra a célebre distinção entre dever moral e dever jurídico, sendo o primeiro um dever de consciência e o segundo um dever externo, um dever em relação ao outro, esclarecendo então que o dever para com os outros é um dever jurídico, enquanto o dever consigo mesmo é o dever moral estrito (BOBBIO; VIROLI, 2007). É perfeitamente plausível dos direitos” (BOBBIO; VIROLI, 2007, p. 42).
} 
Ao responder a provocação intelectual de Viroli, Norberto Bobbio declara que, se naquele momento ainda tivesse alguns anos de vida, estaria tentado a escrever " $A$ era dos deveres" e posicionou-se claramente no sentido de que

não existem direitos sem deveres correspondentes, afirmando ainda que, para que a Declaração dos Direitos do Homem não seja, como disseram tantas vezes, um elenco de desejos pios, deve existir uma correspondente declaração dos deveres e das responsabilidades daqueles que devem fazer valer os direitos" (BOBBIO; VIROLI, 2007, p. 42b).

Instalado então por Maurizio Viroli (2007) a se pronunciar sobre qual seria o primeiro dos deveres de um cidadão em um decálogo dos deveres, Bobbio responde que este seria o dever de respeitar os outros, a superação do egoísmo pessoal, ou seja, aceitar o outro. Seria, para Bobbio, a tolerância aos outros. Para ele, o dever fundamental é dar-se conta de que você vive em meio aos outros.

A tolerância a que se refere Bobbio deve ser compreendida como o reconhecimento moral dos direitos do outro e deve se tornar o fundamento central da construção e aplicação do Direito e da democracia na contemporaneidade, na medida em que ao olhar o diferente, particularmente para os fins do trabalho o indivíduo ou a pessoa que traz em si a diferença enquanto singularidade decorrente do gênero e da sexualidade, a tarefa central da democracia constitucional inclusiva consiste em produzir condições para legitimar os direitos decorrentes desta diferença e que nenhum direito seja negado por ela ou em decorrência dela, salvo quando a igualdade demandar o tratamento diferente por conta das suas diferenças.

Isso claramente se põe em relação aos direitos humanos como direitos de defesa, contra o Estado, mas contra também o arbítrio privado, seja ele de outro indivíduo ou da sociedade. Em última instância, o Estado está legitimado, inclusive pela via judicial, a interferir na esfera privada para garantir que a igualdade de orientação sexual será garantida, possibilitando o acesso às mesmas prerrogativas a que arranjos conjugais heterossexuais possuam, estabelecendo igualdade de direitos e deveres.

Aqui, os direitos humanos não são somente direitos de defesa, mas também direitos de

dizer que aqui ele retoma, sem dizê-lo, a dicotomia ética de convicção/ética da responsabilidade, sendo o dever moral relacionado à primeira e o dever jurídico relacionado à segunda. Para os fins deste trabalho e deste ponto aqui trabalhado, são os deveres políticos dos integrantes da comunidade política, dentre eles os impedimentos eleitorais e a inelegibilidades, deveres jurídicos, por serem sempre um dever com o outro e com a comunidade, inobstante sejam fundamentados em princípios jurídicos como a República e a democracia que são igualmente dotados de elevado conteúdo moral e ético-político. Importa-nos, contudo, tratar da sua exigibilidade e da extensão desta àqueles que reclamam o respeito à diferença. 
não discriminação, garantindo o dever do Estado e da sociedade de garantir a igualdade, mesmo no espaço social privado.

No que tange aos direitos de participação política, embora não seja possível criar direitos e responsabilidades que onerem a comunidade política em decorrência de pretensões igualitárias fundadas no gênero e na sexualidade sem um devido processo legislativo, ou seja, sem a construção de um consenso mínimo, neste sentido, apoiado pela maioria política e social, é possível defender que a intervenção judicial pode, e deve, aprofundar e aperfeiçoar mecanismos de ação afirmativa no que tange à participação política fundada nas diferenças de gênero, como fez o Tribunal Superior Eleitoral no que se refere às cotas para candidaturas de mulheres nas eleições.

Há, contudo, uma contrapartida importante e necessária à afirmação da igualdade que respeite diferenças fundadas no gênero e na sexualidade: a necessidade de respeitar os limites ético-jurídicos essenciais para viabilizar a plena participação na vida política no contexto do espaço público.

O respeito aos mesmos deveres e responsabilidades que todos os cidadãos e cidadãos devem observar funda-se na reciprocidade extraída do próprio conceito de Estado de Direito, e vincula igualmente àqueles que invocam tratamento fundado na diferença, seja ela de gênero ou de orientação sexual, quando falamos nos direitos de participação política, notadamente nos direitos políticos negativos.

Com efeito, o debate sobre democracia e diferença já permeia toda reflexão da teoria social e política na contemporaneidade e o jurídico não poderia estar isento, tanto destas considerações como dos problemas e tensões a que elas se referem.

Como traz Jean L. Cohen (1996, p. 186),

inicialmente o foco da identidade e do orgulho de grupo por parte de mulheres, gays, negros, e dos diversos grupos de identidade étnica e linguística podia ser entendido como uma reação aos limites da política da inclusão, que pareciam oferecer igualdade formal perante a lei (tratamento igual) e plena participação política somente se o preço fosse a assimilação e a renúncia à particularidade ${ }^{15}$.

Em um momento posterior, Cohen (1996, p. 186b) assevera que

o desenvolvimento e a afirmação de novas interpretações da identidade de grupo aparentemente envolveria uma sofisticada autorreflexão da parte de alguns dos novos atores coletivos em relação aos processos sociais e as relações de poder

\footnotetext{
15 No original em inglês: [...] initially the focus on group identity and pride on the part of women, gays, blacks, and various ethnic and linguistic groups could be understood as a reaction to the limits of the politics of inclusion, which seemed to offer formal legal equality (equal treatment) and full political membership only at the price of assimilation and the renunciation of particularity (...).

envolvidas na formação da identidade e das normas sociais, ${ }^{16}$
} 
Que pode perfeitamente incluir o papel da identidade de grupo da produção e aplicação das normas jurídicas.

Retornando ao pensamento desenvolvimento por Jean L. Cohen (1996, p. 186-187), o objetivo parecia ser o de assegurar "igual oportunidade a todos os participantes destes processos em iguais termos", o que levaria a "política da identidade" a manter um "impulso universalista, impondo um desafio democrático e igualitário à pseudoneutralidade dos modelos culturais existentes, das normas sociais institucionalizadas ${ }^{17}$ e às identidades de grupo (re)conhecidas". ${ }^{18}$

Cohen (1996), no entanto, alerta para o risco para a democracia em tomar-se a diferença como algo em si mesma ou algo que se autojustifique, importando em um respeito naturalístico e mesmo autoritário no sentido de que "devo ser respeitado porque sou diferente e apenas por isso", sem qualquer conexão com ideais de universalidade e publicidade que permeia o espaço democrático no constitucionalismo contemporâneo, conforme podemos ver nas palavras da própria autora:

\begin{abstract}
Hoje, porém, muitos protagonistas da política da identidade parecem ter abandonado a política de inclusão tout court, tanto na sua versão liberal quanto na versão democrática. Auxiliados por teorias que constroem categorias como universalidade, normatividade, igualdade, publicidade, imparcialidade e direitos fundamentais como meras estratégias de poder, partidários da política da identidade simplesmente afirma a diferença per se, como se isso fosse suficiente para obter reconhecimento e privilégios. Atualmente, os particularismos nem se quer se dão o trabalho de fingir serem igualitários, imparciais, intolerantes, ou solidários com os outros, ou mesmo justos. Na sua pior forma, esta política se tornou a própria oposição às políticas igualitárias e democráticas - tal como na emergência de formas de nacionalismo, etnocentrismo, e particularismo de grupo intolerantes ao redor do mundo testemunham. Alguém pode se perguntar se as teorias críticas que desafiaram a feliz consciência do universalismo iluminista e desmascararam o nivelamento e o impulso homogeneizante das concepções que informam as tradições liberal e democrática foram instrumentalizadas pelos antidemocratas ao nos privar da linguagem e dos recursos conceituais indispensáveis para confrontar as afirmativas autoritárias da diferença tão prevalecentes hoje em $\operatorname{dia}^{19}$ (COHEN, 1996, p. 187).
\end{abstract}

\footnotetext{
${ }^{16}$ No original em inglês: [...] the development and assertion of new interpretations of group identity appeared to involve a sophisticated degree of self-reflection on the part of at least some of the new collective actors regardind the social processes and power relations involved in identity formation and the articulation of social norms (...). ${ }^{17}$ É perfeitamente cabível entender aqui que a pseudoneutralidade das normas sociais institucionalizadas abrangeria o Direito e as formas jurídicas existentes, desde sua produção passando pela interpretação e aplicação das normas jurídicas e das relações de tensão entre sistema jurídico e mudança social.

${ }^{18}$ No original em inglês: [...] The aim seemed to be to secure an equal chance for all to participate in these processes on equal terms. As such, "identity politics" retained an universalistic thrust - it posed en egalitarian and democratic challenge to the pseudoneutrality of existing cultural models, institutionalized social norms, and acknowledged group identities.

${ }^{19}$ No original em inglês: [...] Today, however, many protagonists of identity politics seem to have thrown down the gautlet to the politics of inclusion tout court, in both its liberal and democratic versions. Aided and abetted
} 
A discussão trazida por Jean Cohen (1996) e a ideia de deveres correlatos aos direitos, inclusive o dever de respeitar o próximo, se associam para tratar da ideia de que é preciso respeitar o diferente e promover a diversidade que se possam conciliar pacificamente as diferenças, mas é preciso também que os diferentes respeitem as normas institucionalizadas necessárias à convivência no espaço público democrático dentro do constitucionalismo contemporâneo.

Como diz Katya Kozincki (2004, p. 343), ao desdobrar o conceito de cidadania a partir da democracia radical,

cidadão é aquele que se identifica com a gramática de conduta da respublica, como interesse público. A cidadania, dentro desta perspectiva, funciona como um elemento articulador entre as diferentes posições de sujeito que os agentes sociais ocupam na sociedade, permitindo a construção de uma identidade comum, ao mesmo tempo em que respeita a liberdade individual.

A igualdade, assim, é uma via de mão dupla, que recai sobre a maioria em respeitar os direitos das minorias, mas também das minorias de respeitar as bases fundantes da democracia constitucional e do espaço público por ela instituído, inclusive quanto aos direitos e deveres como membro pleno da comunidade política e os direitos humanos de pessoas dentro e fora do próprio grupo identitário minoritário.

É nesse ponto que se faz uma conexão necessária e imprescindível da convivência entre igualdade e diferença e a existência de parâmetros mínimos de coesão, social e política, definidos pela democracia constitucional, particularmente a partir dos direitos de participação política e dos limites que eles impõem ao poder político e ao uso dele a ser feito por atores sociais, hegemônicos ou minoritários.

Ao resguardar as regras do jogo e possibilitar a ampla e livre participação cidadã, os direitos políticos em uma democracia constitucional são um elemento de reciprocidade que une diferentes grupos em torno do mesmo processo.

E aqui, por mais que os diferentes, particularmente no que tange à orientação sexual, reclamem uma proteção de acordo com suas próprias singularidades e as reivindiquem na

by theories that construe the very categories of universality, normativity, equality, publicity, impartiality, and basic rights as mere strategies of power, partisans of identity politics simply assert difference per se, as if that were sufficient to merit recognition and entitlements. Nowadays particularisms do not even bother to pretend to be egalitarian, impartial, tolerant, or solidary with others, or even fair. In its worst guise, this politics has turned into the very opposite of egalitarian and democratic politics - as the emergence of virulent forms of nationalism, ethnocentrism, and intolerant group particularisms all over the world witness. One begins to wonder whether the critical theories that challenged the happy consciousness of Enlightenment universalism and unmasked the leveling and homogenizing thrust of concepts informing the liberal and democratic traditions, have played into the the hands of antidemocrats by depriving us of the language and conceptual resources indispensable for confronting the authoritarian assertions of difference so prevalent today. 
forma de direitos humanos fundamentais de diversas ordens, como demonstrado até aqui, os direitos de participação política, inobstante também abertos a transformações e aplicações decorrentes de identidade de gênero, são instrumentos de recondução da tensão entre homogeneidade e diferença a padrões constitucionalmente normatizados de universalidade e de igualdade e, portanto, juridicamente exigíveis, inclusive pela via jurisdicional.

Aliás, como se manifestou a Ministra Rosa Weber no julgamento conjunto das ADC 29 e 30 e da ADI 4578, em fevereiro de 2012,

\begin{abstract}
O escopo da inelegibilidade não é punir. A norma jurídica não tem no indivíduo seu destinatário primeiro. O foco é outro. O foco, a meu juízo, é a coletividade, buscando preservar a legitimidade das eleições, a autenticidade da soberania popular e, em última análise, assegurar o processo de concretização do Estado Democrático de Direito.
\end{abstract}

Ainda segundo a Min. Rosa Weber, na seara eleitoral, e mais precisamente no campo das inelegibilidades, os princípios constitucionais prevalentes são a proteção do interesse público e da coletividade, antes do interesse individual e privado (WEBER, 2012).

Neste sentido, cabe também resgatar trecho do parecer da Procuradoria Geral Eleitoral no julgamento do Recurso Especial Eleitoral número 24564, quando se afirma categoricamente que:

\begin{abstract}
No presente caso - não é fastidioso repetir - a candidata à Prefeitura de Viseu trava relação homoafetiva com a atual Prefeita, que, aliás, já está no segundo mandato. Fosse a relação constituída entre um homem e uma mulher, seja por matrimônio ou concubinato, e ninguém ousaria hastear argumento contrário à proibição estampada no preceptivo constitucional; a ninguém assaltaria a dúvida quanto à flagrante vulneração à ratio do dispositivo multicitado.

In casu, será que o fato dos integrantes da relação pertencerem ao mesmo sexo evita a utilização da máquina administrativa em favor do companheiro, evita a formação das oligarquias familiares, do continuísmo, da perpetuação no cargo, da inversão dos postulados republicanos, em verdadeira res domestica?

A resposta afirmativa fere de morte o art. $14, \S 7^{\circ}$, da Carta Magna. ${ }^{20}$
\end{abstract}

Considerando todo o exposto nesta seção do trabalho, parece que a única coisa a acrescentar em relação ao raciocínio desenvolvido pela Procuradoria Geral Eleitoral no Recurso Especial Eleitoral 24564/2004 é que utilizar-se da diferença de gênero e de orientação sexual como inversão dos postulados republicanos e imposição de uma razão privada particularista e excludente em relação à comunidade política não somente fere de morte a ratio do art. 14 , parágrafo $7^{\circ}$, da Constituição brasileira, mas toda a ideia de igualdade

\footnotetext{
${ }^{20}$ Reprodução de parte da manifestação da Procuradoria da República no Pará no julgamento do Caso Viseu no Tribunal Regional Eleitoral do Pará, reproduzida por sua vez a partir da manifestação do Vice-Procurador-Geral Eleitoral no REsp Eleitoral 24564. In: Tribunal Superior Eleitoral. Relatório do Recurso Especial Eleitoral número 24564. Relator: Min. Gilmar Mendes. Data do julgamento: 1\%/10/2004.
} 
fundada em reciprocidade e respeito, a partir da qual se tenta construir a democracia constitucional contemporânea.

\section{Conclusões}

A identidade de gênero e de orientação sexual é um valor que informa cada vez mais as demandas igualitárias do Direito Constitucional Contemporâneo, chegando, inclusive, a fundamentar uma nova concepção substantiva de Estado de Direito.

Mas, ao mesmo tempo em que as diferenças fundadas no gênero e na sexualidade merecem a proteção contra a discriminação e a afirmação de direitos que respeitem as singularidades fundadas nas identidades delas decorrentes, é preciso também manter as pretensões de igualdade de gênero e de orientação sexual conectadas com as pretensões universalistas e com os demais valores republicanos e humanistas que informam a democracia constitucional contemporânea.

No campo dos direitos políticos, isto implica no respeito à soberania popular, ao critério majoritário e às regras que mantêm idôneo o processo de disputa político-ideológica por meios das eleições e por meio dos direitos e deveres inerentes à política democrática, como a livre expressão política e a contenção dos abusos de poder econômico e político no processo eleitoral.

Dentro da tradição recente do constitucionalismo democrático brasileiro, impedir a perpetuação de um mesmo grupo familiar à frente do governo, seja ele local, estadual ou nacional, é um imperativo que se impõe a todos os indivíduos e grupos da comunidade política que queiram ser parte integrante do processo democrático.

Isto se aplica a qualquer pessoa ou grupo, independentemente de cor, raça, sexo, gênero e orientação sexual. Aqui, a identidade de grupo baseada em gênero e na sexualidade deve respeitar as diretrizes fundantes da democracia constitucional, ou seja, à igualdade de oportunidades e à aplicação paritária das regras políticas a todos os atores sociais.

Invocar a diferença de gênero e de orientação sexual para eximir-se ou escusar-se de cumprir uma obrigação cidadã e republicana, altamente informada pelo dever de respeitar os outros participantes do processo político, é abandonar os mesmos ideais universalistas e igualitários por vezes invocados por pessoas e grupos ligados à identidade sexual e de gênero na busca pela afirmação de direitos. 
Inelegibilidade Eleitoral e Reconhecimento da União Homoafetiva como Entidade Familiar: Análise das Tensões Entre Igualdade e Diferença no Julgamento do Recurso Especial Eleitoral 24564 no Tribunal Superior Eleitoral

Em outras palavras, é negar a reciprocidade e entregar ao faccionismo e ao particularismo, que divide em vez de compartilhar, e que nega tanto a soberania popular quanto a própria igualdade cidadã e democrática. 


\section{Referências}

BOBBIO, Norberto et al. Dicionário de política. 13. ed. Brasília: Ed. da UnB, 2007. 2 v. BOBBIO, Norberto; VIROLI, Maurizio. Direitos e deveres na República: os grandes temas da política e da cidadania. Rio de Janeiro: Elsevier, 2007.

BRASIL. Tribunal Regional Eleitoral do Pará. Recurso Especial Eleitoral REsp Eleitoral número 24564. Sentença de primeira instância do caso Viseu. Relator: Min. Gilmar Mendes. Julgamento: $1 \% / 10 / 2004$.

. TSE. Recurso Especial Eleitoral número 24564. Julgado em $1^{\circ}$ de outubro de 2004.

CAMPINHO, Bernardo Brasil. Direitos humanos, gênero e sexualidade no Estado Constitucional de Direito. Texto disponível em: http://bdtd.ibict.br/vufind/Record/UERJ 75fbf09d2d70c085d8aa53f5168fc3d4. Acesso em 23 de agosto de 2015.

CANOTILHO, José Joaquim Gomes. Direito constitucional e teoria da constituição. Coimbra: Almedina, 1999.

COHEN, Jean L. Democracy, difference and the right of privacy. In: BENHABIB, Seyla (Org.). Democracy and difference: contesting the boundaries of the political. Nova Jérsei: Princeton University Press, 1996.

DAHL, Robert. Sobre a democracia. Tradução Beatriz Sidou. Brasília: Ed. da UnB, 2001.

DALLMAYR, Fred. Para além da democracia fugidia: algumas reflexões modernas e pósmodernas. In. SOUZA, Jessé (Org.). Democracia hoje: novos desafios da teoria democrática contemporânea. Brasília: Editora Universidade de Brasília, 2001.

KOZINCKI, Katya. Democracia radical e cidadania: repensando a igualdade e a diferença a partir do pensamento de Chantal Mouffe. In: FONSECA, Ricardo Marcelo (Org.). Repensando a teoria do estado. Belo Horizonte: Fórum, 2004.

MENDES, Gilmar Ferreira. Curso de direito constitucional. 4. ed. São Paulo. Saraiva, 2009.

MOUFFE, Chantal. A política tem a ver com o conflito. Carta Maior, 8 set. 2010. Entrevistada por Mercedes López San Miguel do Página/12. Disponível em: <http://www.cartamaior.com.br/templates/materiaMostrar.cfm?materia_id=16943>. Acesso em: 12 mar. 2013.

REPÚBLICA DE GUATEMALA. Constitución Política reformada por Acuerdo Legislativo No. 18-93 del 17 de Noviembre de 1993. July 20, 2011. Disponível em: <http://pdba.georgetown.edu/constitutions/guate/guate93.html>. Acesso em: 14 dez. 2011.

SARLET, Ingo Wolgang. A eficácia dos direitos fundamentais. 7. ed. Porto Alegre: Livraria do Advogado, 2007.

SANTOS, Josedac Bezerra dos. Chantal Mouffe e a filosofia política. Revista Cult. Texto disponível em: http://revistacult.uol.com.br/home/2010/03/chantal-mouffe-e-a-filosofiapolitica/. Acesso em 23 de agosto de 2015

SILVA, José Afonso da. Comentário contextual à Constituição. 2. ed. São Paulo: Malheiros, 2006.

WEBER, Rosa. Voto da Min. no julgamento conjunto das ADC 29 e 30 e ADI 4578. In: Agência de Notícias do Supremo Tribunal Federal. Disponível em: $<$ http://www.stf.jus.br/portal/cms/verNoticiaDetalhe.asp?idConteudo=200330\&caixaBusca= N>. Acesso em: 20 fev. 2012. 